\title{
Enzyme-mediated protoplast formation of Cuninghamella echinulata - preliminary studies
}

\author{
MAŁgORZATA BRZEZIŃSKa-RODAK* ${ }^{*}$ MAGDALENA KLIMEK-OCHAB, EWA ŻYMAŃCZYK-DUDA \\ Wrocław University of Technology, Faculty of Chemistry, Wrocław, Poland
}

\begin{abstract}
In this report, we have presented the analysis of the enzymatic methods of protoplasts formation of Cunninghamella echinulata. Hydrolytic enzymes of different origin (i.e. prokaryotic and eukaryotic) such as chitinase (EC.3.2.1.14), lyticase (mix of lytic enzymes), and proteinase K (EC 3.4.21.64) were used for fungal cell wall disruption. An effective protoplast formation was achieved with the following enzyme solutions: chitinase $\left(0.33 \mathrm{U} \cdot \mathrm{ml}^{-1}\right)$, proteinase $\mathrm{K}\left(1.8-3.6 \mathrm{U} \cdot \mathrm{ml}^{-1}\right)$, and lyticase $\left(160 \mathrm{U} \cdot \mathrm{ml}^{-1}\right)$. Fluorescent microscopy was used to evaluate the ability of the tested enzymes to effectively produce protoplasts.
\end{abstract}

Key words: fungal protoplasts, Cuninghamella echinulata, protoplast formation

\section{Introduction}

Fungi are organisms that can serve as models for investigation of physiological processes of organisms of different origin. They are also important for industrial applications as producers of bioactive chemicals. In order to leverage their full potential, their genomes are being modified to analyze gene functions, elucidate metabolic processes, and also for their easy adjustments to biotechnological processes for efficient production of enzymes and metabolites (Koushki et al. 2011). Some studies, however, require the usage of fungal protoplasts-cells coated only with the plasma membrane. Such cells can be formed via enzymatic disruption of cell walls with the use of specific lytic enzymes such as chitinase or lyticase.

Fungal protoplasts have been used as an effective experimental tool in studying the unknown mechanisms and biochemical pathways of syntheses of particular metabolites, especially those that are important for biotechnological applications (Verma et al. 2008). Such forms of fungal cells are necessary for hybridization studies that aim at obtaining organisms that are different from parental features. Genetically improved fungi are also applied in industries in the following processes: lignocellulytic fermentation (Pasha et al. 2007), ergosterol production (Avram et al. 1992), active cellulase production (by the recombinant of Trichoderma reesei and Aspergillus niger (Ahmed and Barkly 2006)), and in the fungal citric acid (Kirimura et al. 1988) or antibiotics production (Sotnikova et al. 1988).

The Cunninghamella genus belongs to the Mucorales order and represents the Cuninghamellaceae family (Zheng and Chen 2001). Cunninghamella genus is of high importance in medical research studies (Srisilam and Veeresham 2003; Asha and Vidyavathi 2009) and in a variety of biotechnological processes (Holland 1999; El-Morsy 2004). Species of this genus may be used as sources of lipids (Lunin et al. 2013), chitin, and chitosan (Andrade et al. 2000; Stamford et al. 2007) or can serve as biocatalysts in various xenobiotics transformations (Zhang et al. 1996; Asha and Vidyavathi 2009). The productivity of these biocatalysts may be improved by genetic manipulation, which requires protoplasts formation. Also, the proper classification of these strains for medical diagnostics and for applications such as studying mammalian metabolism patterns and mimetics often depends on stable protoplasts formation. The Cunninghamella genus includes species possessing unique meta- 
bolic properties such as the ability to metabolize xenobiotics of different structures via primary and secondary pathways (Zhang et al. 1996; Asha and Vidyavathi 2009; Pękala et al. 2012). The economic importance of this genus is confirmed by its application in processes such as oxidation of polycyclic aromatic hydrocarbons (molecules resistant to biodegradation and demonstrating carcinogenic and mutagenic activities) (Cerniglia 1992). Cunninghamella echinulata (synonymous $C$. japonica) strain, in particular, is known to produce $\gamma$-linolenic acid that is used as an anticancer agent (Fakas et al. 2007; Gema et al. 2002; Kavadia et al. 2001; Papanikolau et al. 2007). This strain is also able to hydroxylate the biphenyl oxides (Seigle-Murandi et al. 1991). Cunninghamella echinulata has medical importance as well, since it serves as a model organism for several studies including monensin A (a compound with antibacterial or bacteriostatic activity) metabolism by the mammalian hepatocytes (Asha and Vidyavathi 2009; Pękala et al. 2012). The past decade has brought reports on the pathogenicity of Cunninghamella echinulata discovered, thanks to the molecular methods applied for a clinically relevant species identification. This strain is also likely to be responsible for zygomycosis (these are rare yet serious and potentially life-threatening fungal infections that usually affect the face or oropharyngeal (nose and mouth) cavity) in humans (Alvarez et al. 2009). It is, therefore, important to take a closer look at the physiology and cell structures of this fungus. These experiments usually require the usage of protoplasts, so it is relevant to elaborate an effective method for protoplasts formation of Cunninghamella echinulata, taking into account the specificity of its cell wall structures. The main polysaccharides found in the fungal cell wall are glucans (glucose polymers bound by $\beta$ 1,3-; $\beta$ 1,6-; $\alpha 1$ 1,4-; and $\alpha$ 1,3-glycosidic bonds), chitin ( $\beta$ 1,4- $N$-acetylglucosamine residues polymer), and chitosan composed of deacetylated chitin. Cell wall proteins are glycosylated via $\mathrm{N}$ - or $O$-bonds and are attached to polysaccharides also via covalent links. The structure of the fungal cell wall and its sensibility to enzymatic degradation strongly depend on the age of mycelia and on the cultivation conditions (Diaz-Jimenez 2012). Differences in the cell wall structure are observed among the representatives of the fungal kingdom, even within one species. It is also known that the composition of a fungal cell wall depends on the growth conditions (Scott et al. 2001), and hence it is quite difficult to invent a general procedure for its disruption. That is why almost every strain requires its own conditions for protoplast formation.

Thus, it is crucial to elaborate a method for cell wall degradation of Cunninghamella echinulata that is simple. As we show the application of lytic enzymes is the method which can be applied in order to obtain Cunninghamella echinulata protoplasts. The effectiveness of this particular method is also discussed.

\section{Materials and methods}

\section{Chemicals and enzymes}

The chemicals were purchased from Biocorp (Warszawa, Poland) or POCH (Gliwice, Poland). Enzymes such as chitinase (from Serratia marcescens), lyticase (from Arthobacter luteus), and proteinase K (from Engyodontium album (Tritirachium album)) were purchased from Sigma Chemicals Co.

\section{Microorganism}

The strain of Cunninghamella echinulatawas purchased from DSMZ (Deutsche Sammlung von Mikroorganismen und Zellkulturen, DSM 1905).

\section{Microorganism cultivation}

The Cuninghamella echinulata strain (DSM 1905) was cultivated in a solid medium, which consisted of: agar-agar ( $20 \mathrm{~g})$, soya peptone $(5 \mathrm{~g})$, yeast extract $(5 \mathrm{~g})$, $\mathrm{NaCl}(5 \mathrm{~g}), \mathrm{K}_{2} \mathrm{HPO}_{4}(5 \mathrm{~g})$, and glucose $(20 \mathrm{~g})$ dissolved

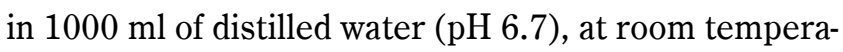
ture for seven days to complete superficial growth into Petri dishes. Then, an Erlenmeyer flask containing $50 \mathrm{ml}$ of liquid medium (as above, except for agar-agar) was inoculated with three small disks $(6 \mathrm{~mm}$ in diameter) cut from the previous solid culture and such cultures were incubated at room temperature with shaking (200 rpm) for three days. After that, $1 \mathrm{ml}$ of inoculum was used for the preparation of the second-stage culture, incubated under stationary conditions $(40 \mathrm{ml}$ of liquid medium, Petri dishes: $\varphi 200 \mathrm{~mm}$ ). After the cultivation time (three days), the biomass was separated by centrifugation $(4000 \mathrm{rpm} / 10 \mathrm{~min})$, washed twice with sodium phosphate buffer $\left(\left(\mathrm{Na}_{2} \mathrm{HPO}_{4}\right.\right.$ and $\left.\mathrm{NaH}_{2} \mathrm{PO}_{4}\right)$ $0.025 \mathrm{M}, \mathrm{pH} 7)$, and then the cells were used in the process of protoplast formation. 


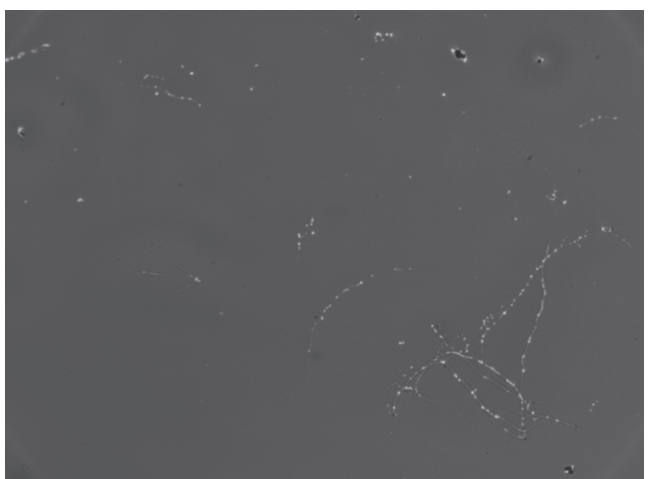

Fig. 1A. Chitinase-mediated protoplast formation: enzyme activity, $0.17 \mathrm{U} \cdot \mathrm{ml}^{-1}$

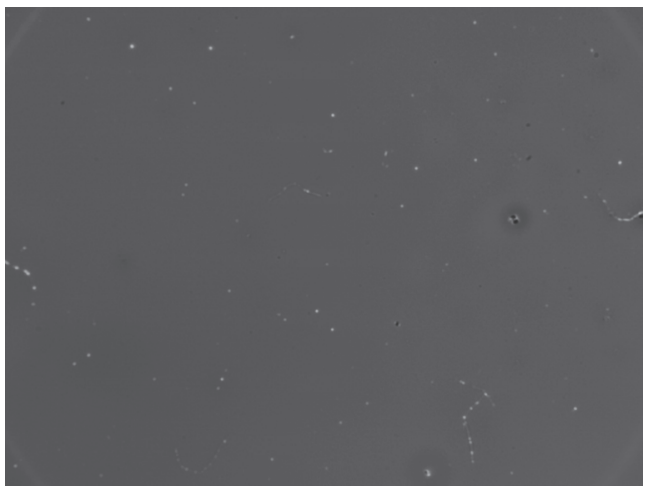

Fig. 1B. Chitinase-mediated protoplast formation: enzyme activity, $0.33 \mathrm{U} \cdot \mathrm{ml}^{-1}$

\section{Protoplast formation}

A total of $0.5 \mathrm{~g}$ of wet, washed cells of Cunninghamella echinulata was resuspended in $1.5 \mathrm{ml}$ of stabilization buffer (0.025 M phosphate buffer, $0.5 \mathrm{M}$ sorbitol). Lytic enzymes ( 5 or $10 \mu \mathrm{l}$ of enzyme solutions: chitinase, $50 \mathrm{U} \cdot \mathrm{ml}^{-1}$; lyticase, $47972 \mathrm{U} \cdot \mathrm{ml}^{-1}$; proteinase $\mathrm{K}, 541.0 \mathrm{U} \cdot \mathrm{ml}^{-1}$; commercially available enzymatic powders with different specific activity) were added and the mixture was incubated in $20 \mathrm{ml}$ glass bottle for $24 \mathrm{~h}$ at room temperature and with shaking at $120 \mathrm{rpm}$. Control probes without the enzymes were performed simultaneously. All probes were performed in triplicate. After the desired time $(24 \mathrm{~h})$, all of the experiments were tested for protoplast formation using fluorescence microscope Olympus BX60. Protoplasts yield was determined with a hemocytometer.

\section{Microscopic analysis}

After enzymatic cell wall disruption, microscopic samples were prepared on the basic microscopic slides and dried carefully under room aeration, which were

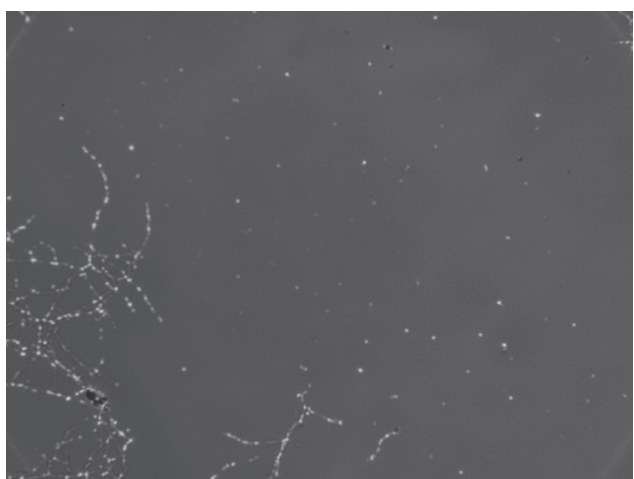

Fig. 2A. Lyticase-mediated protoplast formation: enzyme activity, $160 \mathrm{U} \cdot \mathrm{ml}^{-1}$

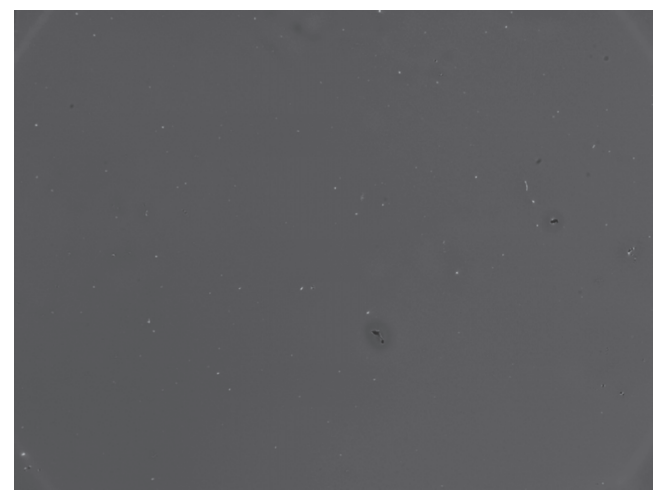

Fig. 2B. Lyticase-mediated protoplast formation: enzyme activity, $320 \mathrm{U} \cdot \mathrm{ml}^{-1}$

then analyzed using a fluorescence microscope Olympus BX60. The best visualization was achieved with the use of polarized light and $50 \times$ magnification lens.

\section{Results and discussions}

Prerequisites for Cunninghamella echinulata protoplasting as well as methods and conditions of elaborated procedures were developed.

Three lytic, commercially available enzymes were tested as tools for cell wall degradation of Cunninghamella echinulata- chitinase, lyticase, and proteinase $\mathrm{K}$. The chitinase (EC.3.2.1.14) turned out to be very effective in hydrolysis of $\beta$-1,4-linkages in chitin and chitosan molecules, but the enzymatic activity toward chitosan was found to strongly depend on the degree and distribution of acetyl side chains (Hartl et al. 2012). This is due to the catalytic features of the enzyme, which depend on the location of $N$-acetyl groups of the sugar units relative to the hydrolyzed glycosidic bond-preferably -1 substitution (Sorbotten et al. 2005). This enzyme at a very low concentration, for example, $0.17 \mathrm{U} \cdot \mathrm{ml}^{-1}$, resulted in 


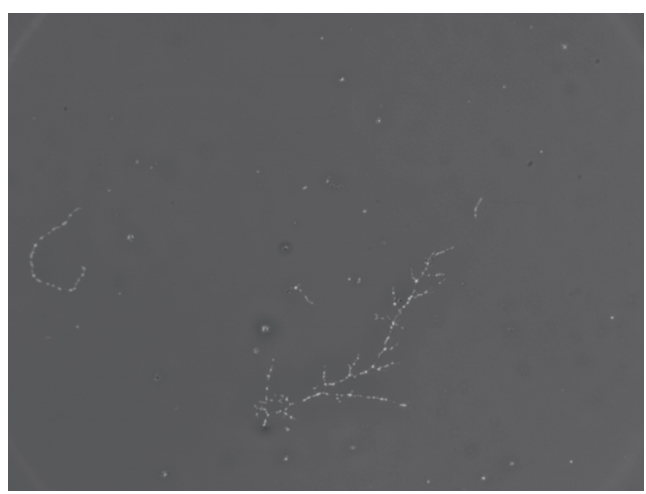

Fig. 3A. Proteinase K-mediated protoplast formation: enzyme activity, $1.8 \mathrm{U} \cdot \mathrm{ml}^{-1}$

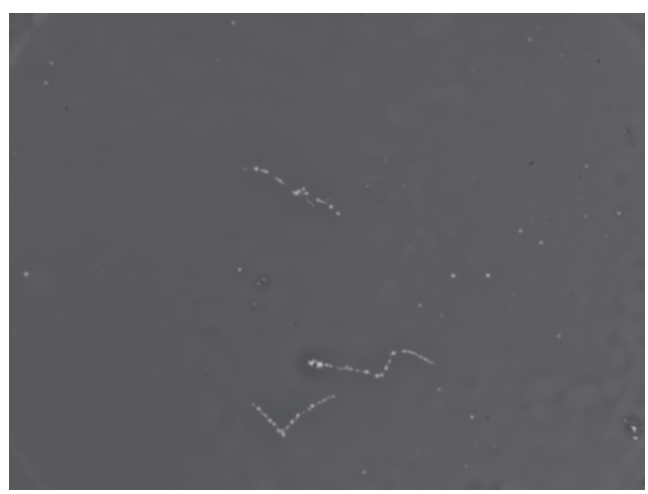

Fig. 3B. Proteinase K-mediated protoplast formation: enzyme activity, $3.6 \mathrm{U} \cdot \mathrm{ml}^{-1}$

a partial removal of the outer coat from fungal cells (the number of formed protoplasts was determined as 0.5 $\times 10^{6}$ ), which is presented in Figure 4A. Whereas when the concentration was increased to $0.33 \mathrm{U} \cdot \mathrm{ml}^{-1}$, it resulted in a complete cell wall degradation (the number of formed protoplasts was determined as $1.5 \times 10^{6}$ ) (Fig. 4B) The amount of chitin converted to chitosan is different for various fungal species. It may also vary with cell type and age of the mycelium. Usually, chitin makes up to $15 \%$ of the fungal cell wall structure. In Mucorales, chitin may contribute to even more than $40 \%$ of the dry weight of mycelium and it is partially deacylated to chitosan (Tan et al. 1996). Hence, to be effective, the procedure of protoplast formation must be selected individually based on the strains. In the case of Cunninghamella echinulata, the first three days are optimal for chitin production; when it exceeds three days, the molar ratio of chitin to chitosan affects the applied chitinase. Cunninghamella echinulata is characterized, among mucoraceous fungi, as a fungus with a high acetyl group content, es-

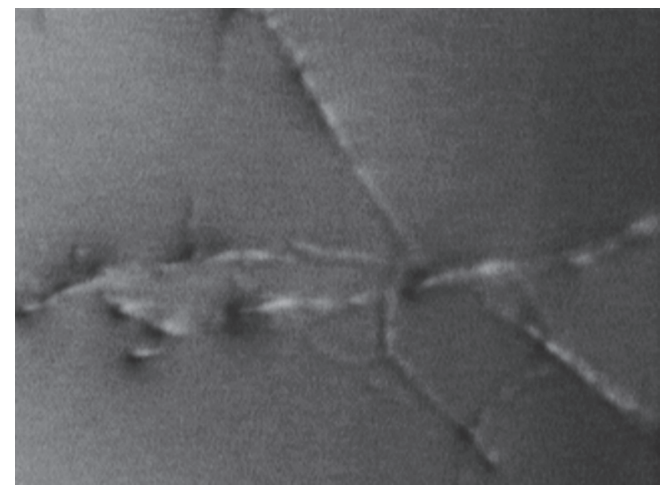

Fig. 4. Cuninghamella echinulata complete cells-control picture

pecially in the early stages of development; therefore, the cell wall of a three-day-cultured mycelium can be effectively hydrolyzed under experimental conditions (Feofilova 2010).

The application of the other lytic enzyme, such as lyticase, also resulted in protoplasts formation, but the effectiveness of this process was lower compared to the chitinase-mediated process. Among Cunninghamella species, $\beta$-glucans were found as components of the chitosan-glucan complex (Nwe et al. 2008), and hence the application of this lytic enzyme was justified. Use of a solution of $160 \mathrm{U} \cdot \mathrm{ml}^{-1}$ of lyticase resulted in a partial removal of the cell wall (Fig. 2A). Unfortunately, increased enzymatic activity resulted in the destruction of sensitive protoplasts (Fig. 2B). This can be explained by the heterogeneity of commercially available lyticase from Arthobacter luteus, which is indeed a mixture of endo- $\beta$ 1-3-glucanase, protease, and mannanase. It is impossible to strictly define the process conditions, especially particular enzymatic activities; therefore, it is difficult to predict the specificity of such a mixture. This might be the reason for the lower activity of enzymes such as chitinase and lyticase. Also, the protoplast degradation is probably due to the proteolytic activity of the lyticase mixture, which eventually leads to cell lysis.

Proteinase $\mathrm{K}$ was the last lytic factor to be tested. This enzyme at concentrations of 1.8 and $3.6 \mathrm{U} \cdot \mathrm{ml}^{-1}$ resulted in a poor cell wall degradation under every condition tested (Fig. 3A, Fig. 3B respectively). This was due to the chemical structure of the fungal cell wall, which, apart from polysaccharides, is also composed of small fraction of proteins. Many cell walls are made up of glycosylphosphatidylinositol(GPI)-anchored proteins, 
but a number of other proteins are also incorporated into the cell wall matrix. The integral proteins present play important roles in cross-linking the matrix together. Majority of the cell wall proteins are glycosylated derivatives, and thus it was reasonable to combine the activity of proteinase $\mathrm{K}$ with glucanase to make protoplast formation more effective. Visualization of the fluorescent microscopy enabled to compare the mycelium without any degradation of the cell wall (Fig. 4) or the mycelium after the proteinase $\mathrm{K}$ action. As can be clearly seen, proteinase $\mathrm{K}$ is an appropriate tool for partial cell wall degradation and, therefore, for stable protoplast formation.

\section{Conclusions}

Summing up, the most effective, economic, and easyto-perform method of cell wall degradation of Cuninghamella echinulata is based upon the chitinase activity as the protoplasting factor. Chitinase is a rather common enzyme present in many living organisms and is also commercially available, which additionally makes an elaborated procedure as simple as possible. Experiments performed have also led to the development of a repeatable protocol of protoplasts formation with the use of proteinase $\mathrm{K}$. This is also important, especially for further studies on the structure of the cell wall of Cuninghamella echinulata.

\section{References}

Ahmed M., Barkly E.I. (2006) Gene transfer between different Trichoderma species and Aspergillus niger through intergeneric protoplast fusion to convert ground rice straw to citric acid and cellulose. Appl. Biochem. Biotech. 135: 117-132.

Alvarez E., Sutton D.A., Cano J., Fothergill A.W., Stchigel A., Rinaldi M.G., Guarro J. (2009) Spectrum of Zygomycete species identified in clinically significant specimens in the United States. J. Clin. Microbiol. 47: 1650-1656.

Andrade V.S., Neto B.B., Souza W., Campos-Takaki G.M. (2000) A factorial design analysis of chitin production by Cunninghamella elegans. Can. J. Microbiol. 46: 1042-1045.

Asha S., Vidyavathi M. (2009) Cunninghamella - a microbial model for drug metabolism studies - a review. Biotechnol. Adv. 27: 16-29.

Avram D., Petcu I., Radu M., Dan F., Stan R. (1992) Electrically induced protoplast fusion for ergosterol producing yeast strain improvement. J. Basic. Microbiol. 32: 369-372.

Cerniglia C.E. (1992) Biodegradation of polycyclic aromatic hydrocarbons. Biodegradation 3: 351-368.

Diaz-Jimenez D.F., Perez-Garcia L.A., Martinez-Alvarez J.A., Mora-Montes H.M. (2012) Role of the fungal cell wall in pathogenesis and antifungal resistance. Curr. Fungal Infect. Rep. 6: 275-282.

El-Morsy E.S.M. (2004) Cunninghamella echinulata a new biosorbent of metal ions from polluted water in Egypt. Mycologia 96: 1183-1189.

Fakas S., Galiotou P.M., Papanikolaou S., Komaitis M., Aggelis G. (2007) Compositional shifts in lipid fractions during lipid turnover in Cuninghamella echinulate. Enzym. Microbiol. Technol. 40: 1321-1327.

Feofilova E.P. (2010) The fungal cell wall: Modern concepts of its composition and biological function. Microbiology 79: 711-720.

Gema H., Kavadia A., Dimou D., Tsagou V., Komaitis M., Aggelis G. (2002) Production of $\gamma$-linolenic acid by Cuninghamella echinulata cultivated on glucose and orange peel. Appl. Microbiol. Biotechnol. 58: 303-307.

Hartl L., Zach S., Seidl-Seiboth V. (2012) Fungal chitinases: diversity, mechanistic properties and biotechnological potential. Appl. Microbiol. Biotechnol. 93: 533-543.

Holland H.L. (1999) Recent advances in applied and mechanistic aspects of the enzymatic hydroxylation of steroids by whole-cell biocatalyst. Steroids 64: 178-186.

Kavadia A., Komaitis M., Chevalot I., Blanchard F., Marc I., Aggelis G. (2001) Lipid and $\gamma$-linolenic acid accumulation in strains of zygomycetes growing on glucose. J. Am. Oil Chem. Soc. 78: 341-346.

Kirimura K., Lee S.P., Nakajima I., Kawabe S.M., Usami S. (1988) Improvement in citric acid production by haploidization of A. niger diploid strains. J. Ferment. Technol. 66: 375-382.

Koushki M.M., Rouhani R., Farsi M. (2011) Genetic manipulation of fungal strains for the improvement of heterologous genes expression (a mini-review). Afr. J. Biotechnol. 10: 7939-7948.

Lunin V.V., Sergeeva Y.E., Galanina L.A., Mysyakina I.S., Ivashechkin A.A., Bogdan V.I., Feofilova E.P. (2013) Biodiesel fuel production from lipids of filamentous fungi. Appl. Biochem. Microb. 49: 46-52.

Nwe N., Stevens W.F., Tokura S., Tamura H. (2008) Characterization of chitosan and chitosan-glucan complex extracted from the cell wall of fungus Gongronella butleri USDB 0201 by enzymatic method. Enzym. Microbiol. Technol. 42: 242-250.

Papanikolau S., Panayotou M.G., Fakas S., Komaitis M., Aggelis G. (2007) Lipid production by oleaginous mucorales cultivated on renewable carbon source. Eur. J. Lipid Sci. Tech. 109: 1060-1070.

Pasha C., Kuhad R.C., Rao L.V. (2007) Strain improvement of termotolerant Saccharomyces cerevisiae VS3 strain for better utilization of lignocellulosic substrates. J. App. Microbiol. 103: 1480-1489.

Pękala E., Kubowicz P., Łażewska D. (2012) Cunninghamella as a microbiological model for metabolism of histamine H3 receptor antagonist 1-[3-(4-tert-butylphenoxy)propyl] piperidine. Appl. Biochem. Biotech. 168: 1584-1593.

Scott C.T., Vergoignan C., Feron G., Durand A. (2001) Glucosamine measurement as indirect method for biomass esti- 
mation of Cunninghamella elegans grown in solid state cultivation conditions. Biochem. Eng. J. 7: 1-5.

Seigle-Murandi F.M., Krivobok S.M.A., Steiman R.L., BenoitGuyod J.L.A., Thiault G.A. (1991) Biphenyl Oxide Hydroxylation by Cunninghamella echinulate. J. Agric. Food Chem. 39: 428-430.

Sorbotten A., Horn S.J., Eijsink V.G.H., Varum K.M. (2005) Degradation of chitosans with chitinase $B$ from Serratia marcescens. Production of chito-oligosacharides and insight into enzyme processivity. FEBS J. 272: 538-549.

Sotnikova I.V., Telesnina C.N., Lebed E.S., Dmitrieva S.V., Zhukov V.G. (1988) Antibiotic production in variants of Penicillium chrysogenum isolated after protoplasting stage and exposure to mutants at the protoplasting stage. Antibiot. Chemot. 33: 211-217.

Srisilam K., Veeresham C. (2003) Biotransformation of drugs by microbial cultures for predicting mammalian drug metabolism. Biotechnol. Adv. 21: 3-39.
Stamford T.C.M., Stamford T.L.M., Stamford N.P., Neto B.B., Campos-Takaki G.M. (2007) Growth of Cunninghamella elegans UCP 542 and production of chitin and chitosan using yam bean medium. Electron. J. Biotechnol. 10: 61-68.

Tan S.C., Tan T.K., Wong S.M., Khor E. (1996) The chitosan yield of Zygomycetes at their optimum harvesting time. Carbohyd. Polym. 30: 239-242.

Verma N., Bansal M.C., Kumar V. (2008) Protoplast Fusion technology and its biotechnological applications. Chem. Eng. Trans. 14: 113-120.

Zhang D., Yang Y., Leakey J.E., Cerniglia C.E. (1996) Phase I and phase II enzymes produced by Cunninghamella elegans for the metabolism of xenobiotics. FEMS Microbiol. Lett. 138: 221-226.

Zheng R.Y., Chen G.Q. (2001) A monograph of Cunninghamella. Mycotaxon 80: 1-75. 